\title{
Spatio-temporal land cover dynamics in the Pantanal assessed using lacunarity analysis on an ERS-1 SAR image time series
}

\author{
Geoffrey M. Henebry \\ Kansas State University \\ Division of Biology/Ackert Hall \\ Manhattan, KS 66506-4901 USA \\ T: $913.532 .7997 \quad$ F: 913.532 .6653 \\ gmh@unix.konza.ksu.edu \\ Hermann J. H. Kux \\ Instituto Nacional de Pesquisas Espaciais (INPE) \\ Caixa Postal 515 \\ 12227-010 São José dos Campos SP Brazil \\ T: 55.123.418977 F: 55.123.218743 \\ hermann@klaus.ltid.inpe.br
}

\begin{abstract}
The Pantanal of Brazil, the largest wetland on the planet, is a disturbance-maintained ecosystem: an unusual topography coupled with a seasonal cycle of flooding and drydown creates a collection of landscapes that are environmentally heterogenous in space and time. Dominant land cover types include freshwater and saline lakes, periodically inundated grasslands, and forested corridors and patches. These cover types are highly heterogeneous in spatial arrangement and in response to inundation. Spatio-temporal analysis of land cover dynamics from Synthetic Aperture Radar (SAR) image time series is relatively new research area but one that will expand given the increasing availability of SAR data. The Pantanal is well suited to microwave remote sensing because land cover types can exhibit great contrasts in backscattering. We have previously shown the efficacy of using lacunarity analysis with SAR imagery for quantifying land cover dynamics. In this presentation we extend that analysis to a total of seven ERS-1 SAR images from December 1992 to November 1993. This period includes both seasonal inundation followed by a significant climatic drought that transformed the spatial structure of backscattering across the landscape. Lacunarity analysis of the SAR image series captures the spatio-temporal rearranging and illustrates how complex land cover change can be quantified within a predictive framework.
\end{abstract}

\section{INTRODUCTION}

The efficacy of Synthetic Aperture Radar (SAR) image time series for environmental monitoring has been amply demonstrated in the past several years [1]. Most of this research has focused on the temporal shifts in backscattering that accompany alterations in land cover and changes in permittivity. Less attention has turned to the spatio-temporal analysis of image series, by which we mean the explicit quantification of temporal change in the spatial structure of an imaged scene. This definition is in contrast to the implicit spatio-temporal analysis found in a sequence of classified images. We seek robust spatio-temporal patterns, landscape trajectories, to use in higher-order change detection algorithms appropriate for environmental monitoring [2,3]. Here we illustrate how lacunarity analysis applied to a seven date SAR image series can uncover some typical spatio-temporal trajectories found within the very dynamic tropical landscape. This study extends our previous work in lacunarity analysis of SAR imagery [4-6].

\section{LACUNARITY ANALYSIS}

Lacunarity indices use multiscale windowing to measure the scale dependency of spatial heterogeneity and anisotropy in binary maps in terms of departures from translational and rotational invariance $[4,7]$. The indices are sensitive to the map density and local aggregation. Higher lacunarity indicates a more sparse, more clumped distribution within the map. Random maps show little persistent spatial structure under multiscale windowing and thus exhibit low lacunarity scores. Conversely, maps containing larger aggregates maintain high lacunarity scores until the extent of sampling window exceeds the extent of the aggregates. Thus for spatio-temporal analyses it is useful to track lacunarity using a constant window size. Anistropy can be estimated by the ratio of lacunarity indices obtained from rectangular windows with extreme but complementary shapes, e.g., $w(l j)$ and $w(j l)$ [6].

\section{STUDY AREA}

The Pantanal is the largest wetland habitat on the planet: an immense assemblage of alluvial fans formed during the Pleistocene, it covers $139,000 \mathrm{~km}^{2}$ in Brazilian states of Mato Grosso and Mato Grosso do Sul [8,9]. The Pantanal is also one of the more radiometrically dynamic landscape in the 
tropics due to extensive seasonal flooding by the Paraguay River and its tributaries. An ecotonal landscape that developed during the Holocene, the Pantanal is a complex mosaic of shallow lakes, periodically inundated grasslands, and islands and elevated corridors of forest, which together support an abundant and diverse fauna of birds, fish, reptiles, and mammals, including four million head of cattle [10].

The Pantanal is remarkable for its reduced declivity (2.5-5.0 $\mathrm{cm} / \mathrm{km})$. Local topographic features $(2-4 \mathrm{~m}$ above the surrounding lands), resulting from either ancient Aeolian sandfields [8] or termite activity [11] are critical for determining habitat for both flora and fauna. Forested ribbons of higher ground known as cordilheiras are never flooded and serve as seasonal refuge for terrestrial animals. Where the water is deep, hydrophytes predominant; in areas with sufficient water flow, productive grasslands emerge [9] Highly permeable soils in the Pantanal lead to a substantial seasonal drydown (June to September) that favors xeric species on elevated soils.

The study area lies in the region of the Pantanal called Nhecolândia, located along the southern tier of the Taquari River alluvial fan. Nhecolândia is remarkable for the hundreds of freshwater and saline lakes that punctuate the landscape. We analyzed three typical landscapes: (1) a large quasiperennial wetland with bordering woodlands, (2) a mosaic of lakes ringed by trees and interspersed among grasslands, and (3) a well formed channel with riparian forest.

\section{METHODS}

Our image time series spanned seven dates (Table 1). The SAR images were georeferenced, ground-range projected, realvalued, 3-look digital data processed by INPE. The nominal ground resolution of these data was $25 \mathrm{~m}$ with a pixel spacing of $12.5 \mathrm{~m}$ in both range and azimuth. For each landscape type the same scene $\left(1024 \times 1024\right.$ pixels $\left.=655 \mathrm{~km}^{2}\right)$ was extracted at each date and registered to the corresponding December 1992 scene using linear offsets. The resulting misregistration was minimal $(<2$ pixels) and lacunarity is robust to misregistration errors when image extent is large relative to pixel resolution. To prepare the data for lacunarity analysis, the quartiles (Q1, Q2, Q3, Q4) of each subimage histogram were calculated and four binary images were thereby generated. Slicing the histogram into even quantiles controls the map density, thereby making lacunarity sensitive only to the scale dependency of aggregation. Lacunarity was estimated using square windows ranging from 1 to 64 pixels (0.0625 ha to 256 ha) with 1000 random samples at each window size. (For more detail on calculation of the lacunarity index, see [4-7].) Anisotropy was estimated using the zerocentered ratio of 4 ha windows of shape $1 \times 64$ and $64 \times 1$. Values close to 0 indicate an isotropic distribution. Values less (greater) than 0 indicate more (less) clumping west to east than north to south.

\section{RESULTS}

In earlier work $[4,6]$ we had seen that most of the spatial heterogeneity was located in Q1 and Q4, corresponding to the lowest and highest backscattering values, while the middle 50 percent of the histogram was dominated by spatially random speckle noise. This was again the case for each landscape examined here. Together Q1 and Q4, although comprising 50 percent of the pixels, accounted for 72 to 91 percent of the total lacunarity. The partitioning of anisotropy, however, was a different matter. There was no significant difference between quartiles at a single date, although there was significant variation in anisotropy over the course of the image series.

If we plot the Q1+Q4 composite anisotropy ratio against the independently determined Q1+Q4 composite lacunarity index, where both were calculated at a maximal window dimension of 64 pixels, we obtain a spatio-temporal pattern that captures some essential elements of the land cover dynamics (Figures 1-3). In each landscape, there is a distinct periodicity of the spatial arrangement of backscattering. Note the counterclockwise trajectory until Day of Year (DOY) 226 for the riparian scene (Fig. 1) and DOY 156 for the lake mosaic (Fig. 2). The divergence from periodicity thereafter likely arises from an extreme drought that struck the Pantanal during the later half of 1993. A similar, though not as clear, pattern of divergence can be seen in the wetland trajectory (Fig. 3).

How do we interpret these trajectories? Lacunarities near zero indicate a nearly random distribution of pixels. These low lacunarity values correspond to the period of peak flooding (DOY 121-156). Note the shift in the wetland (Fig. 3 ) and riparian (Fig. 1) landscapes to lower lacunarity from DOY 261 to 331, corresponding to the peak of dryness. In constrast, the punctuate landscape of the lake mosaic (Fig. 2) registers an increase in aggregation of highest and lowest backscatterers during the drought. The anisotropy time series reveals a similar grouping of the three landscapes. Both the wetland and riparian landscape exhibit an increase in anisotropy due to flooding and an attenuation of anisotropy during drying. Higher anisotropies, however, are observed in the lake mosaic during the drought (Fig. 2).

\section{CONCLUSION}

The spatio-temporal patterns revealed in this study are provocative; however, it is important to recall that these analyses were independent of backscattering magnitude, thus its explicit inclusion might enhance the trajectories. This study shows the utility in extracting latent yet robust spatio-temporal patterns for environmental monitoring, specifically, for the 
definition of nominal behavior, the assessment of disturbance impacts, and, eventually, the predictive modeling of land cover dynamics. Although we do not think that this image series is exhaustively representative of the behavior of the region, the results are promising and we look forward to obtaining additional, longer image series from ERS-2.

\section{ACKNOWLEDGMENTS}

G.M.H. acknowledges support from NSF grant DEB-9527108, a Fulbright Research Fellowship at INPE during 1993-94, and NSF grant BSR-9011662, Long Term Ecological Research at Konza Prairie. H.J.H.K. acknowledges the support of an ERS1 Pilot Project grant from the European Space Agency. The ERS-1 SAR data was processed by and acquired from INPE.

\section{REFERENCES}

[1] European Space Agency, New Views of the Earth: Scientific Achievements of ERS-1, Noordwijk, The Netherlands: ESTEC, 1995.

[2] G.M.Henebry, "Detecting change in grasslands using measures of spatial dependence with Landsat TM data," Remote Sens. Environ. vol. 46, pp.223-234, 1993.

[3] G.M.Henebry and H.Su, "Using landscape trajectories to assess the effects of radiometric rectification." Int. J. Remote Sens., vol. 14, pp. 2417-2423, 1993.

[4] G.M.Henebry and H.J.H.Kux, "Lacunarity as a texture measure for SAR imagery,". Int. J. Remote Sens., vol. 16, pp. 565-571, 1995.

[5] H.J.H.Kux and G.M.Henebry, "Multi-scale texture in SAR imagery: landscape dynamics of the Pantanal, Brazil," in Electronic Digest of IGARSS '94, Piscataway, NJ: IEEE, 1994, pp. 1359-1364.

[6] H.J.H.Kux and G.M.Henebry, "Evaluating anisotropy in SAR imagery using lacunarity functions," Int. Arch. Photogram. Rem. Sens., vol.30, no.7A, pp.141-145, 1994.

[7] R.E.Plotnick, R.H.Gardner, and R.V.O'Neill, "Lacunarity indices as measures of landscape texture," Landscape Ecology, vol. 8, pp. 201-211, 1993.

[8] G. Klammer, "Die paläowuste des Pantanal von Mato Grosso und die pleistozäne Klimageschichte der brasilianischen Randtropen," Zeitschift für Geomorphologie N.F., vol 26, pp. 393-416, 1982.

[9] C.T.Rizzini, A.F.Coimbra Filho, A.Houaiss, Ecossitemas Brasileiros/Brazilian Ecosystems, Rio de Janeiro: Index Editora, 1988.

[10] C.J.R. Alho, T.E. Lacher Jr., and H.C. Gonçalves, "Environmental degradation in the Pantanal ecosystem," BioScience, vol. 38, pp. 164-171, 1988.

[11] V.M.Ponce and C.N. da Cunha, "Vegetated earthmounds in tropical savannas of Central Brazil: a synthesis with special reference to the Pantanal do Mato Grosso," J. Biogeog., vol. 20, pp. 219-225, 1993.
TABLE 1: ERS-1 SAR data from track $210 \&$ frame 3987

\begin{tabular}{|c|c|c|c|}
\hline $\begin{array}{l}\text { Acquisition } \\
\text { Date }\end{array}$ & $\begin{array}{l}\text { Orbit } \\
\text { Number }\end{array}$ & $\begin{array}{l}\text { Center } \\
\text { Latitude }\end{array}$ & $\begin{array}{l}\text { Center } \\
\text { Longitude }\end{array}$ \\
\hline 19921212 & 7369 & $S 19^{\prime \prime} 12^{\circ} 04^{\prime \prime}$ & E304"02'06" \\
\hline 19930220 & 8371 & $519^{\prime \prime} 12^{\prime} 40^{\prime \prime}$ & $E 304^{\circ} 01^{\prime} 26^{\prime \prime}$ \\
\hline 19930501 & 9373 & $S 19^{\prime \prime} 15^{\prime} 00^{\prime \prime}$ & E304" OL' 19" \\
\hline 19930605 & 9874 & $S 19^{\prime \prime} 11^{\prime} 42^{\prime \prime}$ & $\mathrm{E} 304^{\circ} 02^{\prime} 10^{\prime \prime}$ \\
\hline 19930814 & 10876 & $519^{\prime \prime} 11^{\prime} 38^{\prime \prime}$ & $\mathrm{E} 304^{\prime \prime} 0 \mathrm{I}^{\prime} 52^{\prime \prime}$ \\
\hline 19930918 & 11377 & $S 19^{\prime \prime} 12^{\prime} 14^{\prime \prime}$ & $E 304^{\prime \prime}$ Ol' $19^{\prime \prime}$ \\
\hline $1993 \quad 1127$ & 12379 & S19.11' $56^{\prime \prime}$ & $E 304^{\prime \prime} 0 l^{\prime} 55^{\prime \prime}$ \\
\hline
\end{tabular}
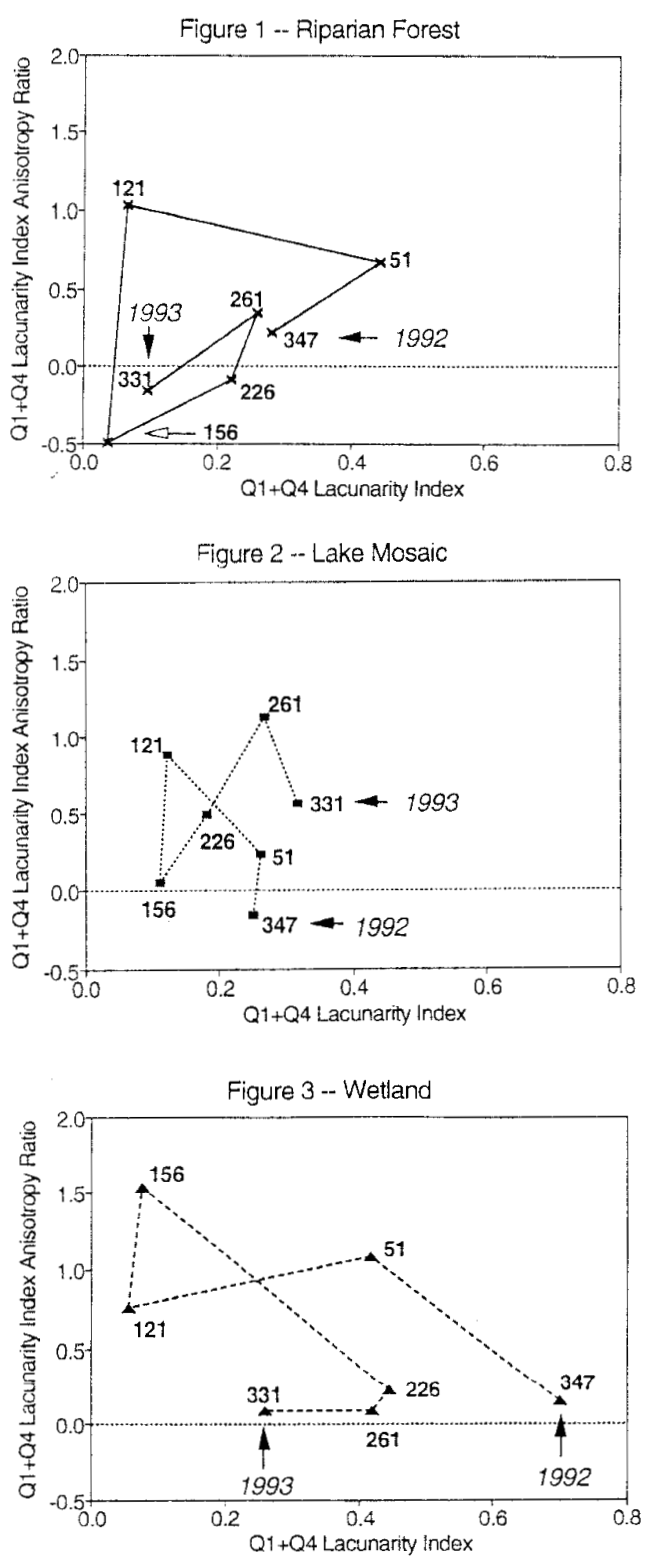